\title{
Risperidone-induced Gingival Bleeding in a Pediatric Case: A Dose-dependent Side Effect
}

\author{
Sabri Hergüner ${ }^{1}$, Hatice Yardım Özayhan ${ }^{2}$, Emire Aybuke Erdur ${ }^{3}$ \\ ${ }^{1}$ Department of Child and Adolescent Psychiatry, Meram Faculty of Medicine, Necmettin Erbakan University, ${ }^{2}$ Department of Psychiatry, \\ Konya Training and Research Hospital, ${ }^{3}$ Department of Orthodontis, Faculty of Dentistry, Selcuk University, Konya, Turkey
}

\begin{abstract}
There are several case reports on risperidone-related bleeding; however, to our knowledge, there is no report about gingival bleeding associated with risperidone in the literature. We presented a case who experienced gingival bleeding when risperidone dose was increased to $0.5 \mathrm{mg} / \mathrm{day}$, and subsided after decreasing the dose to $0.25 \mathrm{mg} /$ day, suggesting a dose-dependent side-effect. The bleeding side effect of risperidone might be caused by several mechanisms, including 5-hydroxytryptamine 2A receptor antagonism. Although bleeding associated with risperidone is rarely reported, clinicians should be aware of this side effect.
\end{abstract}

KEY WORDS: Bleeding; Risperidone; Child; Adverse effects.

\section{INTRODUCTION}

Risperidone has been reported to be effective in management of disruptive behaviors, including hyperactivity, irritability, aggression, and temper tantrums. Increased appetite, weight gain, headache, and sedation are among the most reported adverse effects. Bleeding is a rarely reported side effect of risperidone. Literature search revealed only four published reports of risperidone-related bleeding, including hemorrhagic cystitis, ${ }^{1)}$ nasal bleeding, ${ }^{2,3)}$ and gastrointestinal bleeding. ${ }^{4)}$

We hereby describe the first pediatric case of gingival bleeding during risperidone treatment.

\section{CASE}

An 11-year-old-girl was referred to our out-patient clinic for her hyperactivity, temper tantrums, sleep problems, and self-injurious behaviors. According to her psychiatric assessment and psychometric evaluation, she was diagnosed with mild intellectual disability. She was started on risperidone $0.25 \mathrm{mg}$ /day treatment for her disruptive be-

\footnotetext{
Received: July 17, 2015 / Revised: August 24, 2015

Accepted: August 25, 2015

Address for correspondence: Sabri Hergüner, MD

Meram Tıp Fakultesi, Cocuk ve Ergen Psikiyatrisi AD, Meram,

Konya, Turkey

Tel: +90-533-742-81-50, Fax: +90-332-233-41-40

E-mail: herguners@yahoo.com
}

haviors and two weeks later the dose was increased to 0.5 $\mathrm{mg}$ /day. One-week after the dose increase, she experienced gingival bleeding when she brushed her teeth. Her mother reported that bloodstains were evident on her pillow in the morning. Risperidone was considered to be the reason for bleeding, therefore we decided to reduce the dose to $0.25 \mathrm{mg} /$ day. Gingival bleeding ceased within a week. Because worsening of her behavioral problems, her mother increased the dose to $0.33 \mathrm{mg} / \mathrm{day}$. She experienced gingival bleeding rarely (twice a month) and mildly during this dose regime, therefore we stopped the medication. She received risperidone $0.33 \mathrm{mg}$ /day treatment for 4 weeks with partial response. We decided to change risperidone to methylphenidate; however, her parents refused to continue to the treatment because of their worries about the potential side effects.

Her physical examination and laboratory investigation, including platelet count, were normal. Dental referral did not reveal any cause for her bleeding. She had no history of any bleeding disorder or any other medical condition including current allergies. Her mother reported no family history of bleeding disorders. She was not taking any other medication other than risperidone at the time of the development of bleeding.

(C) This is an Open-Access article distributed under the terms of the Creative Commons Attribution Non-Commercial License (http://creativecommons.org/licenses/by-nc/4.0) which permits unrestricted non-commercial use, distribution, and reproduction in any medium, provided the original work is properly cited. 


\section{DISCUSSION}

There are several case reports about risperidone-related bleeding; however, to our knowledge, there is no report of gingival bleeding associated with risperidone in the literature. We presented a case who experienced gingival bleeding when risperidone dose was increased to 0.5 $\mathrm{mg} /$ day, and subsided after decreasing the dose to 0.25 $\mathrm{mg} /$ day, suggesting a dose-dependent side-effect.

It may be argued that bleeding occurred spontaneously without any obvious cause. However, the chronological relationship between the time of risperidone $0.5 \mathrm{mg} /$ day administration and emergence of bleeding in the absence of an identifiable medical condition suggests risperidone to be the causative agent. There was no other agent likely to be the cause of bleeding, except risperidone, and bleeding ceased when the dose was decreased. Although an etiological relationship between risperidone use and gingival bleeding cannot be drawn from a single case, the Naranjo probability scale score (8) reveals a probable relationship. ${ }^{5}$ )

The bleeding side effect of risperidone might be caused by several mechanisms, including thrombocytopenia and 5-hydroxytryptamine 2A (5-HT2A) receptor antagonism. ${ }^{3)}$ Thrombocytopenia is a known adverse effect of atypical antipsychotics and has also been reported during risperidone. ${ }^{6}$ In our reported case platelet count was normal, therefore, gingival bleeding could not be a consequence of thrombocytopenia. Antagonism of 5-HT2A receptor was suggested to cause bleeding by inhibiting the release of vasoconstrictors from platelets and reducing the platelet aggregation. ${ }^{4)}$ Therefore, we may speculate that risperidone's high affinity to 5-HT2A receptors might have probably resulted gingival bleeding. This case suggests that bleeding associated with risperidone may be a dose-dependent side effect. However, these potential explanations may not describe the entire mechanism of this adverse reaction. It is also possible that she might have some undetermined predisposing factors for bleeding that is triggered by risperidone.

There are several reports on gingival bleeding during antidepressants; ${ }^{7}$ however, this is the first case on gingival bleeding associated with risperidone. Although bleeding is a rare side effect, clinicians should be aware that risperidone may cause bleeding. Risperidone may also increase the risk of bleeding in susceptible patients with a history of coagulation disorders, and with concomitant use of other drugs, including non-steroidal anti-inflammatory drugs, aspirin, or other medications that affect coagulation.

\section{REFERENCES}

1. Hudson RG, Cain MP. Risperidone associated hemorrhagic cystitis. J Urol 1998;160:159.

2. Mowla A, Dastgheib SA, Ebrahimi AA, Pani A. Nasal bleeding associated with fluoxetine and risperidone interaction: a case report. Pharmacopsychiatry 2009;42:204-205.

3. Harrison-Woolrych M, Clark DW. Nose bleeds associated with use of risperidone. BMJ 2004;328:1416.

4. Coskun M, Mukaddes NM. Possible risperidone-related gastrointestinal bleeding or epistaxis in two pediatric cases. $J$ Child Adolesc Psychopharmacol 2008;18:299-300.

5. Naranjo CA, Busto U, Sellers EM, Sandor P, Ruiz I, Roberts $\mathrm{EA}$, et al. A method for estimating the probability of adverse drug reactions. Clin Pharmacol Ther 1981;30:239-245.

6. Semba J, Okui S. Risperidone-induced thrombocytopenia: a case report. Gen Hosp Psychiatry 2009;31:97-98.

7. Yavasoglu I, Kadikoylu G, Bolaman Z. Gingival bleeding due to venlafaxine. Ann Pharmacother 2008;42:144-145. 